\title{
OPTIMASI PERENCANAAN PRODUKSI DENGAN MEMBANDINGKAN METODE GOAL PROGRAMMING DAN METODE FUZZY GOAL PROGRAMMING
}

\author{
Ukurta Tarigan ${ }^{1}$, Meilita Tryana Sembiring ${ }^{1}$, Fernando Tampubolon ${ }^{2}$ \\ Dosen Departemen Teknik Industri ${ }^{1}$, Alumni Departemen Teknik Industri ${ }^{2}$ \\ Fakultas Teknik, Universitas Sumatera Utara \\ Jl. Almamater Kampus USU, Medan 20155 \\ Email : ukurta.tarigan@yahoo.com \\ Email: meilita_tryana@yahoo.co.id \\ Email : fernandotampuboloon@gmail.com
}

\begin{abstract}
Abstrak. PT. ABC merupakan perusahaan yang bergerak dalam produksi bola lampu. Permasalahan yang timbul selama proses produksi adalah sering dihadapkan pada pengambilan keputusan dalam menentukan rencana produksi yang optimal. Hal ini terlihat dari fluktuasi antara selisih jumlah produksi yang terus terjadi menunjukkan perusahaan tidak mempunyai kepastian tentang berapa produk yang akan diproduksi untuk mencapai optimal. Perencanaan produksi yang digunakan perusahaan saat ini tidak dilakukan berdasarkan metode ilmiah, hal ini menyebabkan terjadi penyimpangan atau ketidaktepatan hasil perencanaan dengan kondisi perusahaan. Penelitian dilakukan dengan membuat perencanaan produksi untuk menghitung jumlah produksi optimal dengan model matematis goal programming dan fuzzy goal programming. Hasil yang diperoleh adalah produksi yang lebih optimum yaitu dengan menggunakan metode fuzzy goal programming dengan persentase penyimpangan produksi terhadap penjualan sebesar $0,46 \%$. Optimasi jumlah produk yang dihasilkan dengan memanfaatkan seluruh sumber daya yang dimiliki perusahaan adalah jumlah produksi tertinggi sebesar 209.318 unit untuk tipe stanlee star S-25 dan 297.389 unit untuk tipe stanlee star G-20. Analisis sensitivitas dari parameter waktu penyelesaian produk yaitu sensitif terhadap solusi optimal, tetapi tidak sensitif terhadap fungsi tujuanya yaitu titik optimum.
\end{abstract}

\section{Kata Kunci. Fuzzy, Goal Programming, Optimisasi}

Abstract. PT. ABC is a company engaged in the production of light bulbs. The problems that arise during the production process are often faced with the decision-making in determining the optimal production plan. This can be seen from the fluctuations of the difference between the amount of production that continues to happen to show the company did not have certainty about how many products will be manufactured in order to achieve optimal. Production planning used by the company is not currently done by the scientific method, it causes irregularities or inaccuracies result of planning by the company's condition. Research carried out by making production plans to calculate optimal production quantities with a mathematical model of goal programming and fuzzy goal programming. The result is a more optimum production is by using fuzzy goal programming to production to sales percentage deviation of $0.46 \%$. Optimization of the number of products produced by utilizing all resources owned by the company is the number of peak production of 209318 units for the type of star stanlee S-25 and 297389 units for the type of star stanlee G-20. A sensitivity analysis of the parameters of the turnaround time of product that is sensitive to the optimal solution, but it is not sensitive to their end functionality that is an optimum point.

Keywords. Fuzzy, Goal Programming, Optimization 


\section{Pendahuluan}

Kegiatan produksi sering mengalami kendala. Beberapa kendala diantaranya ketersediaan jumlah bahan baku, jumlah tenaga kerja, ketepatan waktu penyelesaian, dan kapasitas produksi. Perencanaan produksi salah satunya bertujuan sebagai langkah awal untuk menentukan aktivitas produksi yaitu sebagai referensi perencanaan lebih rinci.

PT. ABC merupakan perusahaan yang bergerak dalam produksi bola lampu dengan merek dagang Stanlee Star S-25 dan Stanlee Star G-20. Perusahaan sering dihadapkan pada pengambilan keputusan dalam menentukan rencana produksi yang optimal. Perusahaan belum menerapkan perencanaan produksi yang baik. Selama ini perusahaan melakukan perencanaan produksi dengan melakukan prediksi berdasarkan permintaan pada periode sebelumnya secara sederhana. Hal ini terlihat dari fluktuasi antara selisih jumlah produksi yang terus terjadi menunjukkan perusahaan tidak mempunyai kepastian tentang berapa produk yang akan diproduksi untuk mencapai optimal.

Kebutuhan pelanggan yang fluktuatif yang menyebabkan perusahaan kurang mampu menyesuaiakan kapasitas produksinya dengan permintaan konsumen. Hal ini perlu dianalisis secara kuantitatif karena baik kekurangan produksi maupun kelebihan jumlah produksi mengakibatkan kerugiaan bagi perusahaan. Kekurangan jumlah produksi mengakibatkan berkurangnya keuntungan dari target yang ditetapkan perusahaan dan juga dapat mengakibatkan kurang percayanya konsumen untuk melakukan order kembali ke perusahaan untuk periode berikutnya. Kelebihan jumlah produksi terlalu tinggi mengakibatkan beban biaya guna menyimpan dan memelihara bahan selama penyimpanan di gudang padahal barang tersebut masih mempunyai opportunity cost (dana yang bisa ditanamkan/diinvestasikan pada hal yang lebih menguntungkan).

Penelitian ini akan dilakukan perencanaan produksi untuk menghitung jumlah produksi optimal dengan model matematis fuzzy goal programming. Metode Goal Programming ini digunakan untuk melakukan maksimisasi atau minimisasi sumber daya yang dimiliki perusahaan dengan beberapa fungsi tujuan, dalam metode goal programming juga dikenal istilah variabel deviasional yaitu penyimpangan/deviasi dari pencapaian fungsi kendala yang tidak diharapkan, penyimpangan ini bisa dalam bentuk penyimpangan positif maupun negatif. Contoh variabel deviasional yang tidak diharapkan adalah jumlah tenaga kerja yang seharusnya berjumlah sesuai dengan tenaga kerja tetap. Terdapat deviasi positif dengan diterapkannya sistem kontrak.

\section{Metode Penelitian}

Penelitian ini dilakukan di PT. ABC yang berlokasi di Jalan Pertahanan Lorong 3 No. 7 A,
Medan Amplas. Penelitian dilakukan selama \pm 5 bulan

Jenis penelitian ini adalah penelitian deskriptif yang tergolong pada penelitian kasus (Case Study). Penelitian ini mempelajari secara intensif latar belakang permasalahan guna memberikan gambaran secara mendetail mengenai suatu kasus dengan melakukan pengkajian pada variabelvariabelnya. Objek dalam penelitian ini adalah produk bola lampu yang terdiri dari dua jenis yaitu stanlee star S-25 dan stanlee star G-20 pada PT. $\mathrm{ABC}$.

Instrumen penelitian yang digunakan dalam pengumpulan data adalah checksheet sebagai lembar kerja, stopwatch dan beberapa data sekunder yang dicatat dengan pihak manajemen.

Perhitungan peramlan dilakukan dengan metode time series, dengan perhitungan error menggunakan rumus MAPE (Mean Average Percentage Error

$$
M A P E=\frac{\sum_{t=1}^{n}\left|P E_{t}\right|}{N} .
$$

Perhitungan uji kecukupan data menggunakan tingkat keyakinan $95 \%$ dengan rumus:

$$
N^{\prime}=\left(\frac{\frac{z}{s} \sqrt{N\left(\sum X^{2}\right)-\left(\sum X\right)^{2}}}{\left(\sum X\right)}\right)^{2} \text {. }
$$

\section{Pembahasan}

Pengolahan data yang dilakukan terbagi 3 yaitu:

1. Peramalan permintaan

2. Uji keseragaman dan kecukupan data waktu siklus

3. Penentuan rating factor dan allowance

4. Formulasi fungsi Fuzzy goal programming

\subsection{Peramalan permintaan}

Hasil peramalan permintaan bola lampu stanlee star S-25 (A) dan stanlee star G-20 (B) dapat dilihat pada Tabel 1.

Tabel 1. Rekapitulasi Bobot Prioritas Level Kriteria

\begin{tabular}{lcc}
\hline \multicolumn{1}{c}{ Periode } & A & B \\
\hline Jan 2016 & 181.185 & 272.108 \\
Feb 2016 & 176.766 & 194.489 \\
Mar 2016 & 171.789 & 219.771 \\
Apr 2016 & 166.252 & 297.389 \\
Mei 2016 & 160.157 & 272.108 \\
Jun 2016 & 153.503 & 194.489 \\
Jul 2016 & 146.291 & 219.771 \\
Agu 2016 & 138.520 & 297.389 \\
Sep 2016 & 130.190 & 272.108 \\
Okt 2016 & 121.301 & 194.489 \\
Nov 2016 & 111.854 & 219.771 \\
Des 2016 & 101.848 & 297.389 \\
\hline Total & $\mathbf{1 . 7 5 9 . 6 5 6}$ & $\mathbf{2 . 9 5 1 . 2 7 0}$ \\
\hline & &
\end{tabular}

Berdasarkan Tabel 1 dapat dilihat bahwa data permintaan cenderung fluktuatif mengikuti pola siklis untuk bola lampu tipe A maupun bola lampu tibe B. Perhitungan error menggunakan 
metode MAPE (Mean Average Percentage Error) dengan menggunakan rumus (1).

3.2. Uji keseragaman dan kecukupan data waktu siklus

Hasil uji keseragaman data waktu siklus ditunjukkan pada Tabel 2.

Tabel 2. Rekapitulasi Perhitungan

Keseragaman Waktu Siklus

\begin{tabular}{cccccc}
\hline $\begin{array}{c}\text { No. } \\
\text { Stasiun }\end{array}$ & $\begin{array}{c}\text { Rata- } \\
\text { rata }\end{array}$ & Deviasi & BKA & BKB & Keterangan \\
\hline 1 & 1,58 & 0,053 & 1,686 & 1,474 & seragam \\
2 & 1,71 & 0,060 & 1,828 & 1,588 & seragam \\
3 & 1,71 & 0,060 & 1,828 & 1,588 & seragam \\
4 & 1,92 & 0,057 & 2,036 & 1,808 & seragam \\
5 & 1,89 & 0,061 & 2,009 & 1,763 & seragam \\
6 & 1,94 & 0,028 & 1,994 & 1,882 & seragam \\
7 & 2,03 & 0,066 & 2,159 & 1,897 & seragam \\
8 & 2,22 & 0,053 & 2,326 & 2,116 & seragam \\
9 & 1,80 & 0,000 & 1,800 & 1,800 & seragam \\
\hline
\end{tabular}

Berdasarkan Tabel 2. hasil perhitungan uji keseragaman data diperoleh data seragam yaitu berada antara batas kendali atas dan kendali bawah untuk seluruh stasiun kerja sehingga dapat digunakan untuk pengolahan data.

Uji kecukupan data menggunakan tingkat keyakinan $95 \%$ dihitung dengan menggunakan rumus (2). Hasil uji kecukupan data dapat dilihat pada Tabel 3.

Tabel 3. Rekapitulasi Perhitungan kecukupan data waktu siklus

\begin{tabular}{ccccc}
\hline No. Stasiun & $\boldsymbol{\Sigma} \mathbf{X}$ & $\mathbf{N}$ & $\mathbf{N}^{\prime}$ & Keterangan \\
\hline 1 & 15,80 & 10 & 1,6151 & Cukup \\
2 & 17,08 & 10 & 1,7638 & Cukup \\
3 & 17,08 & 10 & 1,7748 & Cukup \\
4 & 19,22 & 10 & 1,2630 & Cukup \\
5 & 18,86 & 10 & 1,5312 & Cukup \\
6 & 19,38 & 10 & 0,2965 & Cukup \\
7 & 20,28 & 10 & 1,5079 & Cukup \\
8 & 22,21 & 10 & 0,8073 & Cukup \\
9 & 18,00 & 10 & 0,0000 & Cukup \\
\hline
\end{tabular}

Berdasarkan Tabel 3 diatas $\mathrm{N}^{\prime}<\mathrm{N}$ hal ini menunjukkan bahwa data yang dikumpulkan telah cukup.

\subsection{Penentuan Rating Factor dan Allowance}

Penentuan rating factor dilakukan menurut westinghouse. Rekapitulasi perhitungan waktu baku untuk seluruh stasiun kerja ditunjukkan Tabel 4.

Tabel 4. Waktu Normal Pembuatan Bola Lampu
Berdasarkan Tabel 4. diatas, dilakukan perhitungan waktu normal dengan menggunakan data waktu siklus ditambah rating factor. Perhitungan waktu baku diperoleh dari waktu normal dikalikan dengan allowance, perhitungan waktu baku/unit mengetahui waktu baku tertinggi dari seluruh stasiun, maka waktu penyelesaian produk yang terpilih adalah waktu yang terbesar dari stasiun kerja 8 yaitu proses quality control bola lampu dengan waktu 0,04581 menit.

\subsection{Formulasi Fungsi Goal Programming}

Fungsi pencapaian disusun berdasarkan sasaran yang ingin dicapai, maka formulasi untuk bulan Januari 2016 adalah

Min $\mathrm{Z}=\mathrm{d}_{11}^{-}+\mathrm{d}_{12}^{-}+\mathrm{d}_{13}{ }^{-}+\mathrm{d}_{14}^{-}+\mathrm{d}_{15}{ }^{-}+\mathrm{d}_{1}^{+}+\mathrm{d}_{2}^{+}+\mathrm{d}_{3}^{+}+$ $\mathrm{d}_{4}^{+}+\mathrm{d}_{5}^{+}+\mathrm{d}_{6}^{+}+\mathrm{d}_{7}^{+}+\mathrm{d}_{8}^{+}+\mathrm{d}_{9}^{+}+\mathrm{d}_{10}^{+}$

Subject To

$\mathrm{X}_{1}+\mathrm{d}_{11}{ }^{-}-\mathrm{d}_{11}{ }^{+}=176606$

$\mathrm{X}_{2}+\mathrm{d}_{12}{ }^{-}-\mathrm{d}_{12}{ }^{+}=272108$

$\mathrm{X}_{1}+\mathrm{d}_{13}{ }^{-}-\mathrm{d}_{13}{ }^{+}=138531$

$\mathrm{X}_{2}+\mathrm{d}_{14}{ }^{-}-\mathrm{d}_{14}{ }^{+}=242463$

$1.508 \mathrm{X}_{1}+1.240 \mathrm{X}_{2}+\mathrm{d}_{15}{ }^{-}-\mathrm{d}_{15}{ }^{+}=603.647 .301$

$0,04581 \mathrm{X}_{1}+0,04581 \mathrm{X}_{2}+\mathrm{d}_{1}^{-}-\mathrm{d}_{1}^{+}=17640$

$8,31 \mathrm{X}_{1}+10,80 \mathrm{X}_{2}+\mathrm{d}_{2}^{-}-\mathrm{d}_{2}^{+}=25000000$

$0,77 \mathrm{X}_{1}+1,00 \mathrm{X}_{2}+\mathrm{d}_{3}^{-}-\mathrm{d}_{3}^{+}=2000000$

$1,00 X_{1}+1,00 X_{2}+d_{4}^{-}-d_{4}^{+}=2500000$

$1,00 X_{1}+1,00 X_{2}+d_{5}^{-}-d_{5}^{+}=2500000$

$1,00 X_{1}+1,00 X_{2}+d_{6}^{-}-d_{6}^{+}=6000000$

$0,08 X_{1}+0,10 X_{2}+d_{7}^{-}-d_{7}^{+}=2500000$

$0,84 X_{1}+0,11 X_{2}+d_{8}{ }^{-}-d_{8}^{+}=1750000$

$0,04 \mathrm{X}_{1}+0,05 \mathrm{X}_{2}+\mathrm{d}_{9}{ }^{-}-\mathrm{d}_{9}{ }^{+}=150000$

$\mathrm{X}_{1}+\mathrm{X}_{2}+\mathrm{d}_{10}{ }^{-}-\mathrm{d}_{10}{ }^{+}=648.357$

$\mathrm{X}_{1}, \mathrm{X}_{2}, \mathrm{~d}_{1}{ }^{-}, \mathrm{d}_{1}^{+}, \mathrm{d}_{2}{ }^{-}, \mathrm{d}_{2}^{+}, \mathrm{d}_{3}{ }^{-}, \mathrm{d}_{3}^{+}, \mathrm{d}_{4}{ }^{-}, \mathrm{d}_{4}^{+}, \mathrm{d}_{5}{ }^{-}, \mathrm{d}_{5}^{+}, \mathrm{d}_{6}{ }^{-}$, $\mathrm{d}_{6}{ }^{+}, \mathrm{d}_{7}{ }^{-}, \mathrm{d}_{7}{ }^{+}, \mathrm{d}_{8}{ }^{-}, \mathrm{d}_{8}{ }^{+}, \mathrm{d}_{9}{ }^{-}, \mathrm{d}_{9}{ }^{+}, \mathrm{d}_{10}{ }^{-}, \mathrm{d}_{10}{ }^{+}, \mathrm{d}_{11}{ }^{-}, \mathrm{d}_{11}{ }^{+}, \mathrm{d}_{12}{ }^{-}$, $\mathrm{d}_{12}{ }^{+}, \mathrm{d}_{13}{ }^{-}, \mathrm{d}_{13}{ }^{+}, \mathrm{d}_{14}{ }^{-}, \mathrm{d}_{14}{ }^{+}, \mathrm{d}_{15}{ }^{-}, \mathrm{d}_{15}{ }^{+}, \geq 0$

\subsection{Formulasi Fungsi Fuzzy Goal Programming}

Fungsi pencapaian disusun berdasarkan sasaran yang ingin dicapai, maka formulasi untuk bulan Januari 2016 adalah

Max T

Subject to

$0.0000160103 X_{1}+0.0000131694 X_{2}+D N 1-$

DP $1 \geq 6.41$

$\mathrm{T}+0.000018193 \mathrm{X}_{1}+0.0000181793 \mathrm{X}_{2} \leq 9$

$-\mathrm{T}+0.0000004355 \mathrm{X}_{1}+0.0000003351 \mathrm{X}_{2} \geq 0.008$

$\mathrm{T}+0.0000021600 \mathrm{X}_{1}+0.0000016620 \mathrm{X}_{2} \leq 6$

$-T+0.0000005263 \mathrm{X}_{1}+0.0000004053 \mathrm{X}_{2} \geq 0.05$

$\mathrm{T}+0.0000020000 \mathrm{X}_{1}+0.0000015400 \mathrm{X}_{2} \leq 5$ $-\mathrm{T}+0.0000004167 \mathrm{X}_{1}+0.0000004167 \mathrm{X}_{2} \geq 0.04$

$\mathrm{T}+0.0000020000 \mathrm{X}_{1}+0.0000020000 \mathrm{X}_{2} \leq 6$

Wb

$-T+0.0000004167 X_{1}+0.0000004167 X_{2} \geq 0.04$

(Detik) (menit/unit)

$1,86 \quad 0,03102$

$2,09 \quad 0,03484$

$2,28 \quad 0,03792$

$2,34 \quad 0,03905$

$2,14 \quad 0,03561$

$2,23 \quad 0,03715$

$2,38 \quad 0,03972$

$2,75 \quad 0,04581$

$2,31 \quad 0,03848$
$\mathrm{T}+0.0000020000 \mathrm{X}_{1}+0.0000020000 \mathrm{X}_{2} \leq 6$ $-\mathrm{T}+0.0000001695 \mathrm{X}_{1}+0.0000001695 \mathrm{X}_{2} \geq 0.01$

$\mathrm{T}+0.0000010000 \mathrm{X}_{1}+0.0000010000 \mathrm{X}_{2} \leq 7$

$-\mathrm{T}+0.0000000405 \mathrm{X}_{1}+0.0000000324 \mathrm{X}_{2} \geq 0.01$

$\mathrm{T}+0.0000002000 \mathrm{X}_{1}+0.0000001600 \mathrm{X}_{2} \leq 6$

$-\mathrm{T}+0.0000000661 \mathrm{X}_{1}+0.0000005091 \mathrm{X}_{2} \geq 0.06$

$\mathrm{T}+0.0000004360 \mathrm{X}_{1}+0.00000033600 \mathrm{X}_{2} \leq 8$

$-\mathrm{T}+0.0000003571 \mathrm{X}_{1}+0.0000002857 \mathrm{X}_{2} \geq 0.07$

$\mathrm{T}+0.0000010000 \mathrm{X}_{1}+0.0000080000 \mathrm{X}_{2} \leq 4$ 
$\mathrm{T}+0.00022917 \mathrm{X}_{1}+0.00022197 \mathrm{X}_{2} \leq 149.58$

$\mathrm{X}_{1} \geq 176606$

$\mathrm{X}_{2} \geq 272108$

$0 \leq \mathrm{T} \leq 1$

Berdasarkan hasil perhitungan dengan menggunakan software LINDO 6.1. maka dapat diperoleh jumlah produksi optimum dari proses produksi bola lampu tipe stanlee star S-25 (A) dan tipe stanlee star G-20 (B) ditunjukkan pada Tabel 5.

Tabel 5. Rekapitulasi Hasil Jumlah Produksi Optimum

\begin{tabular}{lcc}
\hline \multirow{2}{*}{ Periode } & Jumlah Produk Optimum (unit) \\
\cline { 2 - 3 } & A & B \\
\hline Januari & 176606 & 272108 \\
Februari & 181959 & 194489 \\
Maret & 198316 & 219771 \\
April & 209318 & 297389 \\
Mei & 204980 & 279403 \\
Juni & 187609 & 194515 \\
Juli & 176703 & 219771 \\
Agustus & 197260 & 297389 \\
September & 198316 & 272326 \\
Oktober & 209318 & 194489 \\
November & 203965 & 219771 \\
Desember & 187609 & 297717 \\
\hline \multicolumn{2}{c}{ Total } & \multicolumn{2}{c}{$\mathbf{5 . 2 8 1 . 0 7 7}$} \\
\hline
\end{tabular}

Berdasarkan Tabel 5. diatas diketahui bahwa data jumlah produksi optimum fluktuatif mengikuti data peramalan. Produk tipe A dan tipe B diproduksi melebihi dari data peramalan dan menyisakan stok untuk disimpan, hal ini dikarenakan biaya produksi untuk menghasilkan produk tipe A maupun tipe b lebih murah, sehingga dapat melakukan penekanan biaya produksi untuk barang yang akan dijadikan inventory.

Perhitungan optimasi perencanaan produksi menghasilkan jumlah produksi optimal yang dapat dihasilkan dengan memenuhi fungsi tujuan dan fungsi kendala yang dimiliki perusahaan. Dihitung antara selisih jumlah produksi optimum dengan data produksi untuk mengetahui persentase inventory dapat dilihat pada Tabel 6.

Tabel 6. Selisih Penjualan dengan Hasil Jumlah produksi Optimum

\begin{tabular}{|c|c|c|}
\hline \multirow{2}{*}{ Periode } & \multicolumn{2}{|c|}{ Selisih (Unit) } \\
\hline & $\mathbf{A}$ & B \\
\hline Januari & 0 & 1 \\
\hline Februari & 0 & 0 \\
\hline Maret & 1 & 0 \\
\hline April & 0 & 0 \\
\hline Mei & 1.015 & 7.296 \\
\hline Juni & 0 & 26 \\
\hline July & 97 & 0 \\
\hline Agustus & 15.301 & 0 \\
\hline September & 1 & 219 \\
\hline Oktober & 0 & 0 \\
\hline November & 0 & 0 \\
\hline Desember & 0 & 328 \\
\hline \multirow{2}{*}{ Total } & 16.411 & 7.868 \\
\hline & \multicolumn{2}{|c|}{24.279} \\
\hline
\end{tabular}

Berdasarkan Tabel 6. dihitung persentase jumlah produksi optimum sebesar 24.279 unit dibandingkan dengan data produksi sebesar 5.281.077 unit maka diperoleh sebesar 0,46\%.

\section{Kesimpulan} berikut.

Kesimpulan dari penelitian ini sebagai

1. Trend permintaan produksi untuk bola lampu stanlee star S-25 dan stanlee star G-20 mengikuti pola siklis.

2. Waktu baku dalam penyelesaian produk yang terpilih setelah perhitungan rating factor dan allowance adalah 0,04581 menit.

3. Kebutuhan bahan baku untuk produksi tercapai yaitu lebih kecil dari ketersediaan bahan baku digudang. Kebutuhan jam kerja juga tidak melebihi ketersediaan jam kerja sehingga tidak dipelukan penambahan tenaga kerja tidak langsung.

4. Optimasi jumlah produk yang dihasilkan dengan memanfaatkan seluruh sumber daya yang dimiliki perusahaan adalah dengan jumlah produksi tertinggi sebesar 209.318 unit untuk tipe stanlee star S-25 dan 297.389 unit untuk tipe stanlee star G-20.

5. Analisis sensitivitas untuk parameter waktu penyelesaian produk sensitif terhadap solusi optimal tetapi tidak sensitif terhadap fungsi tujuan. Apabila dilakukan perubahan nilai parameter, solusi optimal akan berubah tetapi fungsi tujuan masih tercapai.

\section{DAFTAR PUSTAKA}

Bhagava, A.K. dkk.. 2015. Fuzzy Goal Programming Techniques for Production Planning in Industry. India: C.C.S. University, Meerut (U.P.).

2015. A Fuzzy Goal Programming Approach for Food Product Distribution of Small and Medium Enterprises. India: C.C.S. University, Meerut (U.P.)

Hillier, Frederick S. dan Gerald J. Lieberman. 1980. Introduction Operation Research. Third Edition. California: Holden Day, Inc.

Introduction Operation Research. Eight Edition. Yogyakarta: ANDI

Johnson, Lynwood A. dan Douglass C. Montgomery. 1974. Operation Research in Production Planning, Scheduling, and Inventory Control. Canada: John Wiley \& Sons, Inc.

Jones, Dylan dan Mehrdad Tamiz. 2010. Practical Goal Programming. London: Springer New York Dordrecht Heidelberg.

Lotfi, Azzabi, dkk. 2014. Fuzzy Goal Programming to Optimization the Multi-Objective Problem. Perancis: University of Angers France.

Marimin, dkk. 2013. Teknik dan Analisis Pengambilan Keputusan Fuzzy dalam 
manajemen Rantai Pasok. Bogor: Penerbit IPB Press.

Mekidiche, Mohammed, Hocine Mouslim dan Abdelkader Sahed. 2013. Appication of Tolerance Approach to Fuzzy Goal Programming to Aggregate Production Planning. Algeria: University of Tlemcen.

Montgomery, Douglas C, dkk. 2008. Introduction to Time Series Analysis and Forecasting. Canada: John Wiley \& Sons, Inc.
Peric, Tunjo, Zoran Babic dan Sead Resic. 2014. A Goal Programming Procedure for Solving Fuzzy Multiobjective Fractional Linear Programming Problem. Croatia: University of Zagreb.

Rad, Mansoureh Farzam dan Hadi Shirouyehzad. 2014.Proposing an Aggregate Production Planning Model by Goal Programming Approach, a Case Study. Iran: Islamic Azad University.

Sukaria, Sinulingga. 2013. Metodologi Penelitian. Medan: USU Press. 